\title{
Effects of Mechanical Activation on the Structure of Nickeliferous Laterite
}

\author{
T. TUnÇ ${ }^{a}$, F. APAYDin ${ }^{b}$ AND K. YILDIZ ${ }^{a}$ \\ ${ }^{a}$ Sakarya University, Metallurgy and Materials Engineering, Sakarya, Turkey \\ ${ }^{b}$ Bartın University, Metallurgy and Materials Engineering, Bartın, Turkey
}

\begin{abstract}
The lateritic nickel ore was activated mechanically in a planetary ball mill and mineralogical analyses of nickeliferous laterite have been studied by particle size analysis, scanning electron microscopy, X-ray diffraction, and the Fourier transform infrared spectroscopy. The results show that the activation procedure led to amorphisation, phase transformation and structural disordering in the laterite structure.
\end{abstract}

DOI: 10.12693/APhysPolA.123.349

PACS: 81.20.Wk, 61.43.Gt, 91.60.Ed

\section{Introduction}

Nickel oxides (laterites) and nickel sulfides comprise the two types of ores used in industrial practice for nickel production. Today, world nickel supply is covered predominantly by sulfide ores $(60 \%$ against $40 \%$ by laterites). Participation of laterite ores, however, has risen from about $10 \%$ before 1950 to about $42 \%$ in 2003 . By taking into consideration that any additional nickel demand is expected to be mainly satisfied by mining of laterite deposits, the optimization of the metallurgical laterite processing methods constitutes a great challenge for the nickel industry [1].

The mechanical activation of minerals makes it possible to reduce their decomposition temperature or causes such a degree of disordering that the thermal activation may be omitted entirely. The mineral activation leads to a positive influence on the reaction kinetics, an increase in surface area and further phenomena. Mechanical activation by high energy milling is an innovative procedure that improves the efficiency of mineral processing because of several factors, most importantly the formation of new surfaces and the creation of lattice defects [2-4].

In this study, the effects of mechanical activation on the structure of nickeliferous laterite were investigated with X-ray diffraction (XRD), particle size analysis, scanning electron microscopy (SEM) and the Fourier transform infrared spectroscopy (FTIR).

\section{Experimental methods and results}

The mechanical activation of lateritic nickel ore from Manisa-Gördes (Turkey) was performed in a Planetary Mono Mill Pulverisette 6 under the following conditions: the weight of sample was $15 \mathrm{~g}$; the weight and diameter of tungsten carbide (WC) balls were $200 \mathrm{~g}$ and $10 \mathrm{~mm}$ respectively; the grinding bowl was $250 \mathrm{~mL} \mathrm{WC}$; the grinding times were $0,15,30,60,90$, and $120 \mathrm{~min}$; the speed

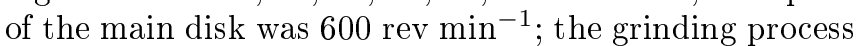
was dry. X-ray diffraction analysis was performed using a Rigaku Ultima X-ray diffractometer and $\mathrm{Cu} K_{\alpha}$ radiation. A JEOL $6060 \mathrm{LV}$ scanning electron microscope was used for morphological analysis of non-activated and activated samples. Shimadzu FTIR spectroscopy was used for FTIR analysis of non-activated and activated (30 and $90 \mathrm{~min}$ ) laterite samples.

$\mathrm{X}$-ray diffraction patterns of non-activated laterite is given in Fig. 1a. As seen in the pattern, quartz and goethite are the major phases while hematite presents as minor phase.

When laterite was subjected to mechanical activation for different milling durations, peak broadening and decrease of intensity occurred, as given in Fig. 1b. This fact is the result of crystal lattice imperfections and disordering. Crystalline size becomes smaller than about one micron by mechanical activation. During high-energy milling, the size of crystals decreased to some critical values. Further energy supply to these crystals of limiting size causes further deformation of crystals, energy accumulation in the volume or at the surface of crystals and subsequent amorphization $[2,5]$. There is not only one effect occurring during the milling process. Because of the contact between powder-ball and attrition between powder-ball-bowl, local temperatures may be increased for higher rev [5].
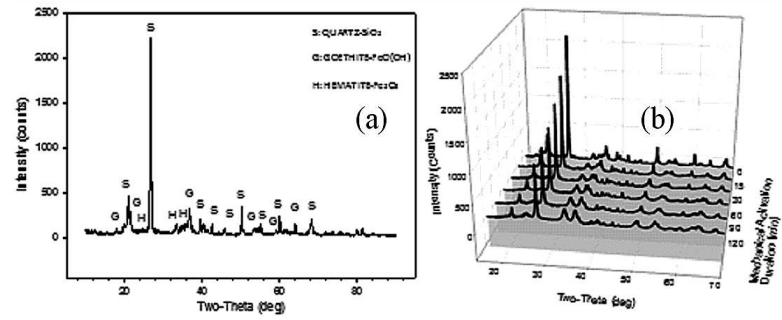

Fig. 1. X-ray diffraction analysis of non-activated (a) and activated (b) laterite samples.

Goethite contains - $\mathrm{OH}$ group and this structure will undergo dehydroxylation as temperature increases. Dehydroxylation of goethite results in hematite formation. In Fig. $1 \mathrm{~b}$, goethite peaks between about $30^{\circ}-40^{\circ}$ become two relatively stronger peaks than the original one. 
This result is evidence that goethite transformed into hematite. Gonzalez et al. [6] claim that mechanical grinding produced dehydration, deformation and crystal fragmentation and these three processes act together in the phase transformation mechanism.

Defining of particle size distribution by using three percentiles is common practice. These are the cumulative distributions of particle size corresponding to $10 \%, 50 \%$, $90 \%$ and specified as $d_{10}, d_{50}, d_{90}$. They are taken directly from mass-based cumulative particle size distribution. Particle size analysis of non-activated and activated laterite samples is given in Table. Increase of mechanical activation duration results in smaller particle than the non-activated one when focused on $d_{90}$ cumulative distribution, but when $d_{50}$ column is taken into account, the particles become larger. Increases in the particle size with mechanical activation may be due to the agglomeration of the particles. When the particle is milled, its surface area increased because of the crushing and forming new surfaces become more reactive. After 60 min of activation, agglomeration started and agglomerates again decayed into smaller agglomerates.

\section{TABLE}

Particle size analysis of non-activated and activated laterite samples.

\begin{tabular}{c|c|c|c}
\hline \hline $\begin{array}{c}\text { Milling duration } \\
{[\mathrm{min}]}\end{array}$ & $d_{10}[\mu \mathrm{m}]$ & $d_{50}[\mu \mathrm{m}]$ & $d_{90}[\mu \mathrm{m}]$ \\
\hline 0 & 2.454 & 5.150 & 44.700 \\
15 & 0.725 & 3.660 & 41.610 \\
30 & 0.719 & 3.750 & 37.230 \\
60 & 0.721 & 3.710 & 33.230 \\
90 & 0.739 & 4.870 & 35.410 \\
120 & 0.735 & 4.400 & 31.360
\end{tabular}

FTIR analysis of non-activated and activated laterite samples is given in Fig. 2. Ruan et al. [7] stated that $3206-3450 \mathrm{~cm}^{-1}$ interval was the hydroxyl stretching region. Band centers of non-activated, $30 \mathrm{~min}$ and $90 \mathrm{~min}$ activated samples are 3149,3235 and $3273 \mathrm{~cm}^{-1}$, respectively. $3236-3206 \mathrm{~cm}^{-1}$ is assigned to the O-H stretching vibration. This band is sensitive to the temperature of dehydroxylation and it is one of the most important bands used for characterization of goethite dehydroxilation. Ruan et al. [8] also stated that in another study, the band centre shifted to higher wave number with increasing temperature. Mechanical activation supply heat energy during activation process and lead to dehydroxilation of goethite in nickeliferous laterite. From Fig. 2, it is clear that band centre shifted to higher wave number with increasing the mechanical activation duration. A shift of band centre to higher position means that strength of bonds is decreased. If the band shifts to a lower position it will result in tighter bonding.

$1250-1750 \mathrm{~cm}^{-1}$ region is characterized as hydroxyl deformation and water bending [8]. For non-activated ore, the band centre at $1643 \mathrm{~cm}^{-1}$ shifted to $1639 \mathrm{~cm}^{-1}$ which belongs to hematite. It means that tighter bonding

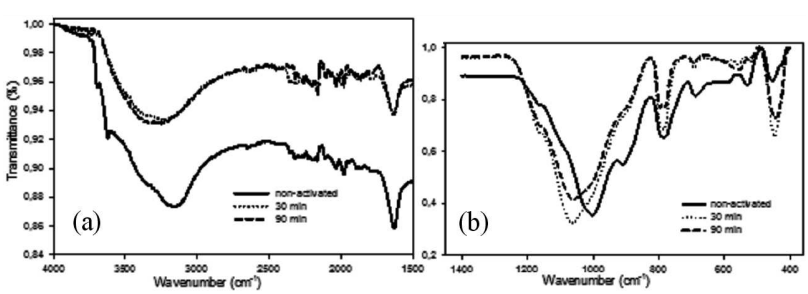

Fig. 2. FTIR analysis of non-activated and activated laterite samples.

occurs in the structure. Same event was observed in the band for hematite at $453 \mathrm{~cm}^{-1}$ for non-activated sample.

At $910 \mathrm{~cm}^{-1}$ centered band belongs to hydroxyl deformation and water bending region and is indicative of the liberation of hydroxyl units from the goethite structure [8].

The band at $782 \mathrm{~cm}^{-1}$ belongs to $\mathrm{SiO}_{2}$. With activation of ore band shifted to higher position that indicates amorphization with taking into account that reduction in band strength. Also $\mathrm{SiO}_{2}$ has band centers at 689, 693 and 694 with respect to increase in duration. The band centers for goethite are at 3450, 3206, 1413, 1269, 888, 798 , and $461 \mathrm{~cm}^{-1}$, those for hematite are at 3434,3227 , 1633,1526 , and $452 \mathrm{~cm}^{-1}$ and the bands for $\mathrm{SiO}_{2}$ are at $1086,1035,795$ and $470 \mathrm{~cm}^{-1}$ [7-9]. But all of them are pure or synthesis one or include other substitutes. Therefore, the band centers observed in our study may show little changes. Changes in the number of position of IR absorption bands are mostly analyzed in terms of structural changes [2].

Scanning electron micrographs (SEM) are shown in Fig. 3. It was clear that the particle size decreased, while mechanical activation duration increased. SEM analysis is in good agreement with particle size distribution data, given in Table. After 60 min of activation, small particles accumulate and are seen as a large particle. At the end of 120 min of activation, agglomerates still exist but there are more small particles in the ore.

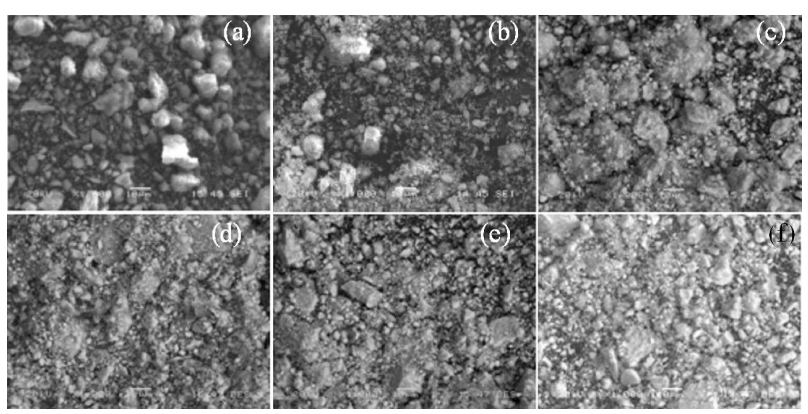

Fig. 3. SEM micrographs for non-activated (a) and activated (b)-(f) for 15, 30, 60, 90 and $120 \mathrm{~min}$, respectively, laterite samples.

As the result, the mechanical activation caused amorphization and disordering in the laterite structure. X-ray 
diffraction analysis and the Fourier transform infrared analysis supported those changes in the structure.

\section{References}

[1] E.N. Zevgolis, C. Zografidis, T. Perraki, E. Devlin, J. Therm. Anal. Calorim. 100, 133 (2010)

[2] P. Balaz, Mechanochemistry in Nanoscience and Minerals Engineering, Springer-Verlag, Berlin 2008, pp. 121, 134, 136.

[3] D. Tromans, J.A. Meech, Miner. Eng. 14, 1359 (2001)

[4] F. Apaydin, A. Atasoy, K. Yildiz, Can. Met. Quarterly 50, 113 (2011)
[5] P. Balaz, Extractive Metallurgy of Activated Minerals, Amsterdam, Elsevier 2000, p. 11.

[6] G. Gonzalez, A. Sagarzazu, R. Villalba, Mater. Res. Bull. 35, 2295 (2000)

[7] H.D. Ruan, R.L. Frost, J.T. Kloprogge, L. Duong, Spectrochim. Acta A 58, 479 (2002)

[8] H.D. Ruan, R.L. Frost, J.T. Kloprogge, L. Duong, Spectrochim. Acta A 58, 967 (2002)

[9] P.S.R. Prasad, K.S. Prasad, V.K. Chaitanya, E.V.S.S.K. Babu, B. Sreedhar, S.R. Murthy, J. Asian Earth Sci. 27, 503 (2006). 